We conclude that surreptitious ingestion of sympathetically acting drugs should be considered in the differential diagnosis of hypertensive attacks.

2nd Department of Internal Medicine, Endocrine Metabolic Unit, S Maria Nuova Hospital, 42100 Reggio Emilia, Italy

ITALO PORTIOLI, MD, professor

ROBERTO VALCAVI, MD, assistant

\section{Punk rocker's lung: pulmonary fibrosis in a drug snorting fire-eater}

While pulmonary damage secondary to intravenous self-administration of drugs is well recognised, disease due to deliberate inhalation of drugs other than for therapeutic purposes is not. We report on a patient who developed pulmonary fibrosis secondary to "snorting" of drugs and inhalation of turpentine or paraffin.

\section{Case report}

A 21-year-old builder's labourer with a two-week history of diffuse chest pain, cough, and purulent sputum was referred for chest radiography. Until three months earlier he had been a full-time drummer in a punk-rock band and had led an irregular existence which ended when he ignited his flat with a cigarette; since then he had been living with his parents. He smoked

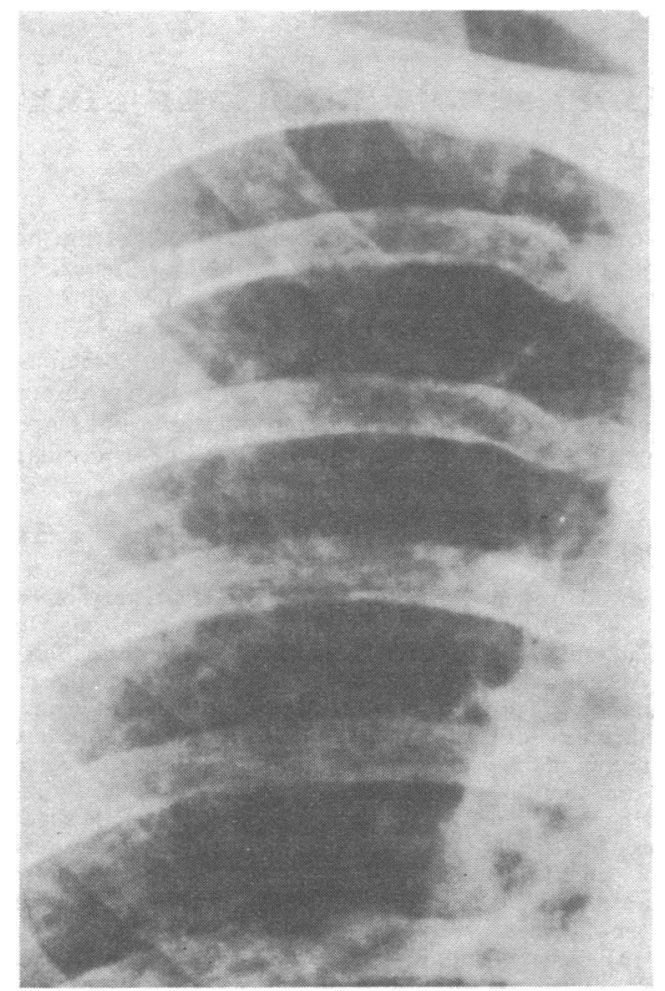

Detail of chest radiograph showing small nodular and irregular infiltrates through the lung.

about 60 cigarettes daily and had regular morning cough and sputum. As part of his act he used to fill his mouth with turpentine or paraffin which he would blow out and ignite. He had taken drugs since he was 16-years-old, often swallowing them with beer. He recalled taking, among others, Mandrax, Tuinal, Dexedrine, DF118, diazepam, and cannabis. He occasionally inhaled powdered drugs-particularly Tuinal, nitrazepam, and cocaine-through a rolled-up pound note (snorting). He had never injected himself. He denied dyspnoea and when seen in the clinic was symptom free.

His chest was wheezy but there were no marks on his arms. Chest radiography showed bilateral small nodular and irregular infiltrates throughout both lungs with no hilar node enlargement (figure). Lung function was completely normal (forced expiratory volume 1.5 litre, forced vital capacity 5.0 litre, and transfer factor $100 \%$ predicted). Haemoglobin concentration erythrocyte sedimentation rate, and blood film gave normal results, as did all blood tests, including for rheumatoid factor, avian precipitins, and viral titres. Tubercle bacilli were not cultured from sputum. Mantoux 1:100 and Kveim tests were negative. Electrocardiography showed no abnormality. Arterial blood showed mild hypoxia with an arterial oxygen pressure of $9 \cdot 6 \mathrm{kPa}$.

A drill biopsy of the lung was performed to make a diagnosis. The specimen showed foci of fibrosis containing clumps of macrophages and clefts lined by bronchiolar epithelium. Some macrophages contained large intracytoplasmic vacuoles compatible with exogenous lipid. There were no granulomas. Several small spicules of material that transmitted polarised light were seen both in alveolar macrophages and in scarred areas but not in vessels.

Two months later he was well with no treatment and chest radiograph and lung function were unchanged. He defaulted from further follow-up.

\section{Comment}

The needle biopsy specimen showed florid pulmonary scarring and intra-alveolar fibrosis with acicular refractile material, probably talc, though the specimen was too small for further analyses. Within the fibrous tissue were macrophages containing empty coalescent vacuoles representing oils removed by organic solvents during the processing, and presumed to be either paraffin or turpentine. There was no intravascular foreign material and it was clear that in our patient inhalation was the only means of administration.

The fibrosis was probably due to the combination of inhalation of paraffin or turpentine in "fire-eating," and of talc, a lubricant and filler in tablets. Although talc is known to cause a pulmonary reaction when inhaled in an occupational setting ${ }^{1}$ and cosmetically, ${ }^{2}$ we have been unable to find any report of diffuse pulmonary fibrosis in a drug-snorter or solely due to the inhalation of the lighter hydrocarbons such as turpentine. Severe lung scarring has, however, been reported in association with the accidental inhalation of liquid paraffin and with the smoking of tobacco containing mineral oils in Guyana ${ }^{3-5}$

As the habit of snorting drugs appears to be prevalent in the lunatic fringe of our society, more cases of this syndrome will probably be recognised, and physicians should be aware of it as a radiological mimic of sarcoidosis in young people.

${ }^{1}$ Morgan WKC, Seaton A. Occupational lung diseases. Philadelphia: W B Saunders, 1979:112.

2 Wells IP, Dubbins PA, Whimster WF. Pulmonary disease caused by inhalation of cosmetic talcum powder. Br $\mathcal{F}$ Radiol 1979;52:586-8.

${ }^{3}$ Pinkerton $\mathrm{H}$. The reaction to oils and fats in the lung. Archives of Pathology $1928 ; 5: 380-401$.

4 Salm R, Hughes EW. A case of chronic paraffin pneumonitis. Thorax $1970 ; 25: 762-8$.

${ }^{5}$ Miller GJ, Ashcroft MT, Beadnell HMSG, Wagner JC, Pepys J. The lipoid pneumonia of blackfat tobacco smokers in Guyana. $Q \mathcal{F} \mathrm{Med}$ $1971 ; 40: 457-70$.

(Accepted 27 May 1981)

City Hospital, Edinburgh EH10 5SB

D R BUCHANAN, MB, MRCP, medical registrar

Department of Pathology, Edinburgh University

D LAMB, MB, MRCPATH, senior lecturer

Institute of Occupational Medicine, Edinburgh EH8 9SU A SEATON, MD, FRCP, director

\section{Britain's biggest ovarian cyst?}

Removal of a giant ovarian cyst may be followed by life-threatening complications. We report the largest ovarian cyst removed in Great Britain with survival of the patient.

\section{Case report}

A 44-year-old nulliparous housewife presented with abdominal swelling that had gradually increased over five years and recently been associated with breathlessness and pain in the legs. She had beer housebound for one year and could not get into bed, but she and her husband had concealed her 
condition because of her fear of doctors. She had written to her general practitioner asking for hypnotics, but he had realised that he had not seen her for years and had gone to her house. On examination he found gross abdominal distension, wasting of the upper half of the body, and oedema of the legs and abdominal wall. He persuaded her to be admitted to hospital.

On admission the clinical appearance (figure) was typical of a giant ovarian cyst. Because of her worsening dyspnoea it required urgent decompression.

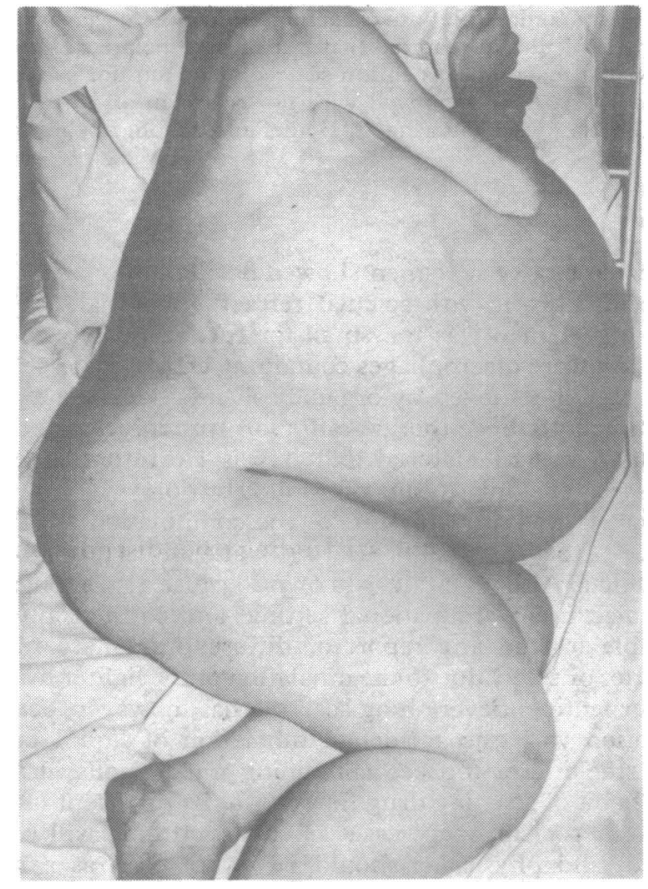

Appearance of patient on admission. She was unable to lie on her back or her right side.

Under general anaesthesia 441 of cyst fluid were drained, and another 13.5 were drained during the subsequent five days. Her condition improved after operation and she was transferred to the general ward, but on day 2 her systolic blood pressure fell suddenly to $40 \mathrm{~mm} \mathrm{Hg}$ and her central venous pressure rose to $20 \mathrm{~cm}$ water. There were signs of pulmonary oedema. She was returned to the intensive care unit and given intermittent positivepressure ventilation, frusemide, and digoxin. She received whole blood, human plasma protein fraction, and dopamine. Haemoglobin, serum electrolyte, and creatinine concentrations were normal, but the blood urea concentration, which had been $10 \mathrm{mmol} / 1(60 \mathrm{mg} / 100 \mathrm{ml})$ on admission, fell to $2.2 \mathrm{mmol} / \mathrm{l}(13.2 \mathrm{mg} / 100 \mathrm{ml})$. Serum albumin concentration (normal on admission) fell to $19 \mathrm{~g} / \mathrm{l}$ and protein to $40 \mathrm{~g} / 1$. Between days 3 and 6 she passed 38.91 of urine, giving a negative fluid balance of 17.41 . Urinary sodium loss rose to $1820 \mathrm{mmol}(\mathrm{mEq}) / 24$ hours.

Systolic blood pressure varied between 60 and $110 \mathrm{~mm} \mathrm{Hg}$. She developed bronchopneumonia, which was treated with erythromycin. By day 12 her cardiovascular state had improved only slightly, but because of suspected peritonitis laparotomy was undertaken. A $5 \mathrm{~kg}$ right ovarian cyst was removed: it had collapsed and become detached from the draining catheter. A cystic ( $1 \mathrm{~kg}$ ) left ovary was also removed, but she was not fit for hysterectomy. A double ellipse of redundant abdominal wall was excised and tracheostomy performed. After operation, in addition to intensive cardiorespiratory support, she received prednisolone and regular peritoneal lavage (cephazolin $1 \mathrm{~g}$ in $500 \mathrm{ml}$ physiological saline). She remained unable to breathe spontaneously until day 24 , but when spontaneous respiration was established her physical and psychological condition rapidly improved. She was transferred to the general ward on the 34th day and went home on the 48th day. She had needed a total of 13 units of whole blood and 45 units of human plasma protein fraction. At follow-up she was well, had been out shopping, and weighed $62 \cdot 2 \mathrm{~kg}$.

The cysts were benign mucinous cystadenomas. The total weight of the right ovary and its contents had been over $62.5 \mathrm{~kg}$.

\section{Comment}

Except for two fatal cases in the eighteenth and nineteenth centuries, ${ }^{1}$ this is the largest ovarian cyst reported in Britain and shows the problems that may follow decompression and removal. ${ }^{1-3}$ Preliminary decompression is not always necessary or desirable, ${ }^{4}{ }^{5}$ but our patient was unfit for a prolonged operation when first admitted. Preoperative digitalisation has been suggested ${ }^{2}$ to prevent cardiorespiratory failure: the reasons for its delayed onset are not clear, but reabsorption of oedema fluid, protein loss, paradoxical movement of the thinned unsplinted diaphragm, and changes in vascular tone may be contributory factors. Potentially fatal ${ }^{1}$ intestinal distension was prevented by excising redundant abdominal wall and using a binder. ${ }^{2}{ }^{5}$ The patient's psychological state necessitated sedation and much nursing support. We emphasise that postoperative cardiorespiratory failure may be delayed in onset, and, since it may be severe and prolonged, we suggest that such large cysts should be treated only in hospitals equipped to deal with it.

We thank the medical and nursing staff of the intensive care unit of Frenchay Hospital for their skill and co-operation, and Mr C M Davidson for permission to report this case.

${ }^{1}$ Symmonds RE, Spraitz AF, Koelsche GA. Large ovarian tumor. Obstet Gynecol 1963;22:473-7.

${ }^{2}$ Hoile RW. Hazards in the management of large intra-abdominal tumours. Ann R Coll Surg Engl 1976;58:393-7.

${ }^{3}$ Hunter DJS. Management of a massive ovarian cyst. Obstet Gynecol $1980 ; 56: 254-5$

4 Bezjian AA, O'Leary JA. A massive (121-lb) ovarian tumour-preoperative siphonage and excision. Obstet Gynecol 1971 ;38:214-6.

${ }^{5}$ Foreman JM. A massive ovarian cyst. Lancet 1960;ii:1200.

(Accepted 19 May 1981)

\section{Frenchay Hospital, Bristol BS16 1LE}

J O DRIFE, MRCOG, senior house officer in general surgery (present appointment: lecturer in obstetrics and gynaecology, Bristol Maternity Hospital, Bristol)

G A TROTTER, FRCS, registrar in general surgery

\section{Intestinal scholechiasis: an unusual fistula}

Scholechiasis was defined by Hope in $1837^{1}$ as meaning the presence of lepidopterous larvae within the human body. This was based on a single case reported by a Scottish surgeon in the eighteenth century when a boy vomited a live caterpillar of the cabbage white butterfly. There are no subsequent reliable records of this phenomenon, probably because such larvae pass through the alimentary tract unnoticed. ${ }^{2}$ We report a case of colocutaneous fistula producing liquid faeces containing copious fruit seeds, dead larvae, and one live caterpillar.

\section{Case report}

A 65-year-old woman presented with a 10-day history of constipation, increasing lower abdominal pain, and abdominal distension. Examination disclosed tenderness in the left iliac fossa and a mass in the left side of the pelvis on rectal palpation. Abdominal radiography and sigmoidoscopy showed no abnormality. Repeat abdominal radiography the next day confirmed dilatation of the large intestine, and at laparotomy an obstructing mass was found at the rectosigmoid junction and relieved by fashioning a transverse colostomy.

After operation she became critically ill with septicaemic shock and acute renal failure, which were successfully treated. During the next week she developed a wound infection, draining copious pus containing many seeds, which were also present at defecation. In the third week two larval structures were found in the pus from the abdominal wound, the first in a dressing and the second in a bag appliance placed over the infected area. At the end of the fourth week a live caterpillar was found on the bottom sheet when she was turned during bed bathing.

The larvae were analysed (JM) and identified as partly digested caterpillars of the family Papilionoidea, probably from the family Pieridae, which includes the cabbage white butterfly. The live caterpillar was identified as coming from the same family. Copious plant seeds found in the pus were identified at Kew Gardens Research Laboratory as seeds of the blackberry.

\section{Comment}

The dead larvae, which undoubtedly came from our patient, were in poor condition and initially thought to be beetle larva. Cautious cleaning, however, showed the ring of crochets of a lepidopterous pseudopod, and a scanning electron micrograph later confirmed a 